April 2008

\title{
Value Hierarchies of Holocaust Rescuers and Resistance Fighters
}

Peter Suedfeld

Stefanie de Best

Follow this and additional works at: https://digitalcommons.usf.edu/gsp

\section{Recommended Citation}

Suedfeld, Peter and de Best, Stefanie (2008) "Value Hierarchies of Holocaust Rescuers and Resistance Fighters," Genocide Studies and Prevention: An International Journal: Vol. 3: Iss. 1: Article 4.

Available at: https://digitalcommons.usf.edu/gsp/vol3/iss1/4

This Articles is brought to you for free and open access by the Open Access Journals at Digital Commons @ University of South Florida. It has been accepted for inclusion in Genocide Studies and Prevention: An International Journal by an authorized editor of Digital Commons @ University of South Florida. For more information, please contact digitalcommons@usf.edu. 


\title{
Value Hierarchies of Holocaust Rescuers and Resistance Fighters
}

\author{
Peter Suedfeld and Stefanie de Best \\ The University of British Columbia
}

\begin{abstract}
There has been considerable theorizing and research on the motivations of individuals who rescued Jews from the Nazi Holocaust. Participants in armed resistance movements, the other major form of active opposition within Nazidominated Europe, have attracted less scientific attention. The study reported here compared members of these two groups using a quantitative measure applied to their own post-war memoirs and interviews. Thematic content analysis was used to score the relative strengths of eleven major value categories in materials produced by forty-seven members of resistance movements and fifty Holocaust rescuers. Benevolence, Universalism, and Spirituality were significantly higher among rescuers than among resistance fighters, with the opposite pattern for Security. There were some gender differences, but no differences based on country of residence. Comparisons with Schwartz's international norm group results are also presented, and the implications of this research with respect to altruism in extreme circumstances are discussed.
\end{abstract}

Keywords: Holocaust, rescuers, resisters, values

\section{Background}

Despite considerable effort to predict, prevent, ameliorate, or stop genocides, ethnic cleansing, and other forms of ethnopolitical violence, and despite the oft-repeated postHolocaust refrain, "Never again," such events have occurred with dismal frequency since 1945. Furthermore, several such events are occurring at any given moment somewhere in the world, many times in countries ignored by the international mass media. It may be that the only effective way to stop them once they begin is through massive armed intervention.

Nevertheless, courageous individuals and groups can at least reduce their impact, thwart their goals, and hinder their progress. Among such people are the individuals who, at great personal risk, rescued Jews from Nazi persecution during World War II; such "righteous among the nations" constitute the most prototypical examples of altruistic behavior. Samuel Oliner and Pearl Oliner characterize a behavior as altruistic when it (1) is directed toward helping another, (2) involves a high risk or sacrifice to the actor, (3) is not accompanied by any external reward, and (4) is voluntary. ${ }^{1}$ These criteria for altruistic behavior were certainly met by Holocaust rescuers during World War II. Holocaust rescuers acted to help Jews, despite great risks to themselves and their families, by sheltering Jews in their own homes, providing false documents, or smuggling Jews to safer locations. ${ }^{2}$

These behaviors were dramatically different from those of the vast majority. Although precise figures cannot be established, only a tiny percentage of nonJews living under German domination engaged in rescue activity. ${ }^{3}$ Many more were collaborators in the persecution, although the majority consisted of bystanders, who engaged neither in directly hurting nor in directly helping the oppressed.

Peter Suedfeld and Stefanie de Best, "Value Hierarchies of Holocaust Rescuers and Resistance Fighters." Genocide Studies and Prevention 3, 1 (April 2008): 31-42. (C) 2008 Genocide Studies and Prevention. doi: 10.3138/gsp.3.1.31 
The passivity of this majority is understandable: quite aside from their own feelings about Jews, the material and psychological gains they may have accrued as a result of the persecution, and the pressures of conformity, most people were understandably reluctant to put their own lives and their family's lives into very serious danger by sheltering others, often total strangers. To do this, as rescuers did, took unusual courage and altruism.

Social scientists have been interested in the situational and dispositional factors that impelled these rescuers to take lethal chances. Most such research has used interview techniques; much less use has been made of standard psychometric instruments. Rescuers are characterized by a greater capacity for extensivity than non-rescuers. Extensivity is defined by the leading researchers in this area as a trait combining a strong sense of responsibility for others and greater attachment to them, heightened empathy for the pain and suffering of others, and a high internal locus of control. ${ }^{4}$ Holocaust rescuers have also been consistently described as feeling greater inclusiveness - "a tendency to feel connected to diverse peoples and groups"5-and as feeling shared humanity with all people. ${ }^{6}$ It has been suggested that this broad identification with others, even strangers from a somewhat different cultural and religious background, is the key feature distinguishing the altruistic Holocaust rescuer from bystanders. ${ }^{7}$

In addition, a psychometric study has found that Holocaust rescuers show differences from bystanders on seven personality variables associated with altruistic behavior: internal locus of control, autonomy, risk taking, social responsibility, empathic concern, and altruistic moral reasoning. Even half a century after the end of World War II, measures of these characteristics distinguished reliably between rescuers and bystanders. ${ }^{8}$ Note, however, that using a bystander comparison group, as most researchers have done, ${ }^{9}$ introduces a confounding factor: some bystanders, who may have felt just as much responsibility, empathy, and altruistic morality as rescuers, may have refrained from action because of conformity, fear, risk aversion, or general passivity in the face of overwhelming legal and military force.

There was, however, another form of active opposition to the Nazi program: participation in armed guerrilla warfare against German troops and their allies, which occurred to some degree in many occupied countries. Members of underground resistance organizations forged documents, transported illegal goods, gathered and transmitted intelligence, bombed railway tracks, assassinated German officers and Nazi collaborators, and participated in ambushes and other types of armed combat. Partisan fighters were usually organized in quasi-military fashion, with a chain of command and methods of receiving mission assignments from their own higher headquarters and sometimes from Britain or other nations at war with the Axis powers. These nations also sent arms, ammunition, radio equipment, and military advisors to partisan organizations, usually by submarine or parachute.

Surprisingly, members of resistance organizations have attracted much less attention from social scientists than have rescuers. There is nothing in the scientific literature to match the extensive studies of the personalities and motivations of those who saved Jewish lives by hiding those in danger. This seems an important omission in our understanding of non-compliant, nonconformist, risk-taking behavior in the face of serious barriers and life-threatening risks. Clearly, resistance was significantly different both from rescue and from fighting in a national army; such activity deserves more systematic study by psychologists and cognate professionals than it has so far received. 
The study reported here applied an unobtrusive and non-reactive technique, previously used in research on (among others) Holocaust survivors and political leaders, to provide new information about rescuers and the much less studied, but equally interesting, category of anti-Nazi risk takers: partisans, individuals who joined underground resistance movements in Nazi-ruled countries.

It is likely that the decision to engage in either rescuing or resistance behavior was influenced by a number of complex, interacting situational and personality factors. For example, religious and political leaders were able to rally individuals, and even communities, to adhere to precepts contrary to those enforced by the Nazis and their collaborators; in other cases, fortuitous encounters with desperate refugees (or aversive encounters with arrogant Nazis) moved bystanders to become active, despite their fear and reluctance. What Holocaust rescuers and partisans had in common was that, unlike most of their compatriots, they took action against the Nazis, despite extreme risks. One might also argue that both types of action fit some of the criteria for altruistic behavior-clearly in the case of rescuers, and in a less traditional way among partisans, for whom direct assistance to individual victims was not the central goal but who voluntarily fought for their compatriots' liberation.

Hostility toward the Nazis did not necessarily imply pro-Jewish attitudes. There were partisan units, especially in Eastern Europe, who shared the Nazis' antiSemitism even while they fought the German military. Such groups (e.g., the Narodowe Sily Zbrojne or NSZ, a Polish underground organization) sometimes combined battle against the German occupation with the mass murder of Jews, which, in the case of the NSZ, extended to killing returning Holocaust survivors after the end of the war. ${ }^{10}$

At the same time, there were also partisan organizations that welcomed Jewish fighters and fighting units into their ranks and tried to help such units by supplying them with arms when that was possible. ${ }^{11}$ And although many, perhaps most, rescuers acted in revulsion against the persecution of the Jews, others were quite anti-Semitic. Some exploited and abused the refugees they were hiding; others, while benevolent to those particular Jews, treated them as exceptions to a general rule that Jews were undesirables whose presence in the country was unwanted. ${ }^{12}$

It is also important to note that rescue operations and armed resistance were not mutually exclusive. Some partisan groups also engaged in rescuing and hiding Jews; ${ }^{13}$ some rescuers, on occasion, used violence to liberate or safeguard their charges. But, although there are such "fuzzy boundary" examples, on the whole it seems reasonable to expect that predominant aspects of the two groups would show some differences between those who risked their lives primarily to hide and shelter the defenseless and persecuted and those who risked theirs by armed attacks against the troops and military supplies of the invaders.

Resistance fighters are a particularly appropriate comparison group because they exclude those bystanders-mentioned previously-who may have been altruistically inclined but, because of fear or other factors, did not actually engage in anti-Nazi behaviors. Thus we can compare two groups, both with strongly oppositionist attitudes toward the Nazis, and both with the courage to risk their lives in order to thwart Nazi goals, but with distinctly different choices as to their actions: one peaceful, the other violent. No previous study has attempted a systematic comparison between these two groups.

In order to study these differences, we applied one kind of thematic content analysis ${ }^{14}$ to archival materials generated by rescuers and resistors after the war. 
Thematic content analyses allow for the measurement of objective, nomothetic features from idiographic, qualitative sources; they make possible such standard research procedures as random sampling of materials, assessment of inter-scorer and test-retest reliability, and application of measures of statistical significance and power. Scoring systems exist for a wide variety of cognitive, emotional, motivational, and personality variables. ${ }^{15}$

In the study reported here, thematic content analysis was performed on memoirs written by and interviews with Holocaust rescuers and members of resistance groups. The variable chosen for measurement was the ordering of values in the individual's value hierarchy, values being the desirable, trans-situational goals, varying in importance, that serve as guiding principles in people's lives. Currently the most widely used scoring system is that of Shalom Schwartz, ${ }^{16}$ which covers seventy-five specific values subsumed under ten major categories: Power, Achievement, Hedonism, Stimulation, Self-Direction, Universalism, Benevolence, Tradition, Conformity, and Security. Schwartz intended the ten motivationally distinct types of values to include all the core values recognized in cultures around the world, ${ }^{17}$ and they have, indeed, reliably shown general recognition (although differing patterns of salience) across cultures and genders. ${ }^{18}$ Although we used Schwartz's taxonomy, the reminiscences of many Holocaust survivors and the literature on rescuers led us to add another category, Spirituality, scored on the basis of references to God, religious tenets, or supernatural entities and considered non-universal by Schwartz.

Schwartz has argued that personal values can lead individuals to act altruistically in situations where such behavior contradicts their own narrow interests, explaining individual acts of heroism in extreme situations such as the Holocaust. The current study explores whether the two different kinds of heroic behavior discussed above are associated with different patterns of individual values.

Similarities and differences between the value hierarchies of Holocaust rescuers and those of resistance fighters were evaluated by comparing the mean value ratings of each group on the categories developed by Schwartz. We expected to find that Holocaust rescuers emphasize Universalism, a value category that includes the values "social justice" and "equality." This hypothesis is based on earlier reports that rescuers are strongly inclusive and have a sense of a common humanity among diverse groups of peoples. ${ }^{19}$ We also predicted that rescuers would value Benevolence, a category that includes the values "helpful" and "responsible," more than resistance members would. This hypothesis is in accordance with findings that rescuers feel strongly responsible for others ${ }^{20}$ and had been taught adherence to an ethic of caring from an early age. ${ }^{21}$ Last, we expected that partisan fighters would place greater emphasis on Security than Holocaust rescuers. The Security category includes the values of Patriotism and National Security, which seem central to resistance activities but not necessarily to rescues.

We also looked for differences in value hierarchies related to gender and country of residence. Scholars using qualitative methods have not reported systematic differences among Holocaust rescuers based on sociocultural or demographic factors, ${ }^{22}$ and quantitative studies have not analyzed gender-related personality variables among rescuers; ${ }^{23}$ it was possible that such effects might be revealed by the analysis of value hierarchies.

Although our primary focus was on comparing rescuers and partisans, we were also interested in comparing the value hierarchies of both groups with the pan-cultural norms published by Schwartz and Bardi. ${ }^{24}$ One would expect that self-selected groups 
engaged in such unusual and dangerous activity might have a value profile quite different from universal norms.

\section{Method}

\section{Procedure}

Each subject was categorized on the basis of his or her role during World War II, as either a rescuer of Holocaust victims or a member of a fighting resistance group. Other independent variables considered were gender (male or female), religious affiliation, and country of residence during the war.

The dependent variables were the mean ratings of each of the eleven value categories.

\section{Subjects}

The ninety-seven subjects of this study were either rescuers of potential victims of Nazi persecution or members of a fighting resistance organization during World War II. Table 1 presents distributions of the sample across countries of residence.

\section{Data Sources}

The narratives were obtained from several sources. Ten personal narratives were published memoirs written by the rescuer or resister; eight unpublished memoirs were obtained from the Imperial War Museum in London. A number of personal narratives came from published collections of interviews with Holocaust rescuers, conducted in the native language of the subject and later translated into English. Twenty-nine such interviews were conducted by Gay Block and Malka Drucker, ${ }^{25}$ eight by Mark Klempner, ${ }^{26}$ and two by Kristen Renwick Monroe. ${ }^{27}$ Sixteen interviews were obtained from an archive collected forty to fifty years after the war on behalf of the United States Holocaust Memorial Museum, ${ }^{28}$ nineteen from the European Resistance Archive, ${ }^{29}$ and an additional five from the Imperial War Museum. All memoirs and interviews were published or collected between 1945 and 2006.

Table 1. Countries of residence at the outbreak of World War II.

\begin{tabular}{lll}
\hline & & Group \\
& Rescuers & Resisters \\
\hline Austria & 0 & 3 \\
Belgium & 6 & 2 \\
Channel Islands & 0 & 6 \\
Czechoslovakia & 2 & 0 \\
Denmark & 2 & 0 \\
France & 5 & 8 \\
Germany & 5 & 3 \\
Hungary & 2 & 0 \\
Italy & 0 & 6 \\
Netherlands & 17 & 3 \\
Norway & 0 & 1 \\
Poland & 11 & 12 \\
Slovenia & 0 & 3 \\
\hline
\end{tabular}


An effort was made to balance the different types of data sources included in each subject category. Five memoirs (mean number of pages =79.4) and forty-five interviews (mean number of extracts $=22.7$ ) were used to obtain the rescuer data; thirteen memoirs (mean number of pages $=89.7$ ) and thirty-four interviews (mean number of extracts $=31.2$ ) were used to obtain the resister data. There were no significant differences in the number of pages per book $(t(16)=-0.23, p>0.05)$ or extracts per interview $(t(77)=-1.28, p>0.05)$ between subject categories.

\section{Scoring}

The narratives were scored by a trained scorer using a values scoring sheet as a scoring manual. Fifty-five of the values were taken from Schwartz's list. Two of Schwartz's values, "moderate" and "broad-minded," were excluded because they did not seem relevant, and eighteen values that do seem relevant were added: hard work, perseverance, competitiveness, humor, boredom, self-doubt, dissension, anger, detachment, assertiveness, respect for others, patriotism, isolation, safety, discovering one's true self, religious membership, solitude, and belief in God. Each of these values was assigned to one of the eleven overarching value categories proposed by Schwartz.

Whenever a value was explicitly mentioned or implied in a personal narrative, it was recorded on the scoring sheet. Values mentioned in each of the eleven value categories were then summed and divided by the number of pages in the memoir, or the number of extracts in an interview, and expressed as a percentage that was then used in the statistical analysis. To test for scoring reliability, a second trained scorer independently scored every tenth scored passage, using the same guidelines. Interscorer reliability was $r=0.85$ or higher for every value. A between-groups analysis of variance (ANOVA) was performed to analyze differences in the value hierarchies of rescuers and resistance members. To analyze differences in the value hierarchies of rescuers and partisans, each value category was rank-ordered according to the frequency of its appearance in the particular narrative. Mean rank order was then calculated for each value category.

Because there were unequal numbers of subjects in the gender and nationality groups, homogeneity of variance could not be assumed. Therefore, these variables were analyzed using Welch's $t$-test with an alpha level of $p=0.05$. All data were analyzed using SPSS.

\section{Results}

The value hierarchies of rescuers and partisans showed several differences (see Table 2). As predicted, rescuers placed higher emphasis on the categories Benevolence and Universalism; also as predicted, partisans placed greater emphasis on Security. An unanticipated difference emerged as well: rescuers placed significantly greater emphasis on Spirituality. There were no significant differences in the remaining value categories.

Table 3 shows the value hierarchy rankings of rescuers, those of resisters, and the pan-cultural norms reported by Schwartz and Bardi. ${ }^{30}$ Some of the rankings show major differences between the pan-cultural norms and one or both of the anti-Nazi activist groups.

Women in our study endorsed all value categories except Power and Achievement more strongly than men did (see Table 4). None of these differences was statistically significant. 
Table 2. Mean value ratings

\begin{tabular}{lllll}
\hline \multicolumn{4}{c}{ Group } & \\
Value Category & Rescuers Mean $(S D)$ & Resisters Mean $(S D)$ & $F(1,96)$ & $p$ \\
\hline Power & $0.12(0.11)$ & $0.13(0.11)$ & 0.13 & $\mathrm{~ns}$ \\
Achievement & $0.12(0.14)$ & $0.16(0.13)$ & 2.24 & $\mathrm{~ns}$ \\
Hedonism & $0.10(0.11)$ & $0.12(0.16)$ & 0.35 & $\mathrm{~ns}$ \\
Stimulation & $0.10(0.09)$ & $0.13(0.12)$ & 1.64 & $\mathrm{~ns}$ \\
Self-direction & $0.11(0.15)$ & $0.13(0.14)$ & 0.30 & $\mathrm{~ns}$ \\
Universalism & $0.22(0.20)$ & $0.13(0.14)$ & 5.76 & 0.02 \\
Benevolence & $0.36(0.23)$ & $0.23(0.20)$ & 9.11 & 0.00 \\
Tradition & $0.01(0.03)$ & $0.01(0.02)$ & 0.06 & $\mathrm{~ns}$ \\
Conformity & $0.08(0.09)$ & $0.07(0.08)$ & 0.44 & $\mathrm{~ns}$ \\
Security & $0.28(0.22)$ & $0.39(0.27)$ & 4.73 & 0.03 \\
Spirituality & $0.13(0.16)$ & $0.04(0.06)$ & 14.87 & 0.00 \\
\hline
\end{tabular}

Table 3. Value hierarchies: Rank orders

\begin{tabular}{llll}
\hline & & \multicolumn{2}{c}{ Current } \\
Value Category & Pan-cultural Norm & Rescuers & Resisters \\
\hline Benevolence & 1 & 1 & 2 \\
Self-direction & 2.5 & 7 & 7 \\
Universalism & 2.5 & 3 & 4 \\
Security & 4 & 2 & 1 \\
Conformity & 5 & 10 & 9 \\
Achievement & 6 & 6 & 3 \\
Hedonism & 7 & 8 & 8 \\
Tradition & 8 & 11 & 11 \\
Stimulation & 9 & 9 & 6 \\
Power & 10 & 5 & 5 \\
Spirituality & Not ranked & 4 & 10 \\
\hline
\end{tabular}

Table 4. Value ranks by gender

\begin{tabular}{lll}
\hline & & Group \\
Value Category & Men & Women \\
\hline Benevolence & 2 & 2 \\
Self-direction & 7 & 5 \\
Universalism & 3 & 3 \\
Security & 1 & 1 \\
Conformity & 10 & 10 \\
Achievement & 4 & 6 \\
Hedonism & 8 & 4 \\
Tradition & 11 & 11 \\
Stimulation & 6 & 7 \\
Power & 5 & 8 \\
Spirituality & 9 & 9 \\
\hline
\end{tabular}


Differences in value hierarchies depending on the survivors' place of residence shortly before the outbreak of the war showed no statistically significant differences.

\section{Discussion}

\section{Limitations}

Before discussing the results and their implications, it is appropriate to acknowledge the limitations of this study. Perhaps the most important of these has to do with sampling. Our sample sizes are relatively small, and the sample is restricted to those rescuers and fighters who have written their memoirs, or with whom interviews have been recorded. Such individuals may be more likely than other former anti-Nazi activists to be comfortable in written and oral expression, to be educated, to live in easily accessible communities, and to have maintained good mental and physical health.

Former partisans who participated in interviews with the US Holocaust Memorial Museum seem likely to be sympathetic to Jews, which was not true of all resistance groups; as we have pointed out, some actually combined fighting the Germans with murdering Jewish refugees or would-be volunteers whom they encountered. ${ }^{31}$ For these reasons, it is possible that our sample of resisters is more sympathetic to Jews, and therefore more similar to rescuers (who, we hypothesize, were generally not antiSemites), than the entire population of underground fighters. A more representative resistance sample might have shown more pronounced differences from rescuers.

Finally, the materials used were published or collected at varying times after the war. Although value hierarchies are theoretically quite stable over time, it is possible that the results would have been somewhat different if the participants could have been interviewed closer to the end of the war. Regrettably, both rescue and resistance are still needed. They are occurring in various locations around the world, so that gathering such data is feasible.

\section{Findings and Implications}

Let us now turn to what we found. The data support the hypothesis that Universalism and Benevolence dominate the value hierarchies of Holocaust rescuers. Both values would be expected, intuitively as well as on the basis of earlier research, to be high among people who risked their own lives to save others on the basis of a perception of shared humanity. Benevolence values also provide the internalized motivational basis for cooperative and supportive social behaviors (e.g., working for the welfare of others; being genuine and sincere; being a close, supportive friend; and valuing emotional intimacy ${ }^{32}$ ), such as those necessary to live with a Jewish refugee hidden in one's home. Although Benevolence is also consistently rated as the most important value pan-culturally, ${ }^{33}$ it would be interesting to assess its ranking in a sample of perpetrators or bystanders in post-Holocaust situations of ethnic or religious persecution.

Universalism is particularly relevant to the behaviors of Holocaust rescuers, as it is functionally most important when individuals must relate to, and feel concern for the welfare of, individuals with whom they do not readily identify ${ }^{34}$-in this case, Jewish targets of persecution, who were culturally and religiously different from their nonJewish rescuers. Of the eleven value categories, Universalism, which includes values such as "equality" and "social justice," best approximates the concept of inclusiveness and the perception of a common bond among all mankind-qualities that previous 
researchers have frequently cited as the key feature distinguishing Holocaust rescuers from bystanders. ${ }^{35}$

However, neither Benevolence nor Universalism was dominant among people who took up arms to combat foreign invaders of their homeland. Universalism, in particular, could hardly be expected among a group that engaged in combat, sabotage, and assassination against an occupying foreign army. Thus, the lower ranking of this value among partisans, as compared to both rescuers and the pan-cultural norm, is not surprising.

Resistance fighters, possibly motivated more by political and patriotic values than by altruism as traditionally defined, were predicted to, and did, rank Security significantly higher than rescuers did. Security (controlling impulses and avoiding risks) was, in fact, high among the members of both groups, implying that their activism was influenced by recognition of the dangers and demands of opposing Nazi dominance. The behavioral expression of that opposition presumably differed because of the divergent importance of other values, personality characteristics, and situational factors.

The difference between rescuers and resistance members in the ranking of Spirituality was unexpected. Spirituality has not been identified as a primary motivator in previous research on rescuers, although individual rescuers have mentioned religious tenets or the personal influence of clergy. Our finding of differences in Spirituality reflects different levels of religious affiliation in our sample: $54 \%$ of the rescuers but only $21 \%$ of the resisters claimed membership in a religion. No religious affiliation was mentioned by $26 \%$ of rescuers and $49 \%$ of resisters, while $20 \%$ of rescuers and $30 \%$ of resisters indicated that they were atheists. By way of comparison, Oliner and Oliner report that although only $15 \%$ of rescuers they studied cited religion as a primary motivator for rescue, levels of religious belief in their samples of rescuers and bystanders were similar (73\% of rescuers and $71 \%$ of bystanders categorized themselves as very or somewhat religious). ${ }^{36}$

Of course, holding spiritual values as important is not the same as being religious, and regarding oneself as religious does not necessarily equate with saying that one is a member of a religion. But the correlation is probably fairly high. The contrast between both samples of rescuers and Oliner and Oliner's bystanders, on the one hand, and our resisters, on the other, is striking.

The role of this category of values needs further investigation. It may be that religious affiliation cannot be taken as a proxy for deeper religious beliefs, or perhaps aspects of Spirituality other than those relating to religion are more relevant to the decision to save the persecuted. The low level of religious affiliation among resisters may also be related to the prominence of Communists and other extreme leftists in some resistance movements.

Both resisters and rescuers ranked Power more highly than the pan-cultural norm group. Power, which emphasizes control over people and resources, should indeed be more important to individuals who are willing to risk severe punishment in pursuit of their values than to those who conform to the dictates of authority even when those dictates violate the moral and legal rules in force only a short time earlier. Similarly, the low ranking of Conformity among both rescuers and partisans makes sense.

In a seeming paradox, both anti-Nazi groups ranked Self-Direction much lower than did the pan-cultural norm groups. The reasons for this are not clear; it may be that both groups considered their behavior to have been guided by moral, religious, political, or patriotic norms rather than merely by their own autonomous will (one frequently cited 
comment by rescuers has been, "I had no choice but to help"). It is also possible that many people involved in anti-Nazi activities viewed themselves as part of a larger whole, rather than as individuals acting of their own volition. However, although almost all partisan units were organized in quasi-military fashion, many rescuers (especially in the later years of the war) did act alone, without a network of supporters or collaborators. ${ }^{37}$

The finding that value hierarchies did not differ as a function of country of residence indicates that rescuers and resisters were motivated by similar values regardless of the specific national culture to which they belonged. In other words, across Europe, the same values were associated with the same kinds of anti-Nazi behaviors. This is an interesting specific example for unusual subgroups of the general finding that there is high consistency across cultures concerning which values are the most and least important. ${ }^{38}$ It also has implications for identifying potential rescuers and resisters in other genocides, regardless of where they may occur.

Existing data on gender differences in value hierarchies resemble the present trends. A study of men and women in seventy-three cultural groups showed that men rank power and achievement (among other values) more highly than women do, with the opposite pattern for benevolence and self-direction, but also that the differences are small. In general, men tend to emphasize "self-enhancement values," such as power and achievement, which underlie the pursuit of one's own interests; women tend to emphasize the opposite, "self-transcendence values" such as universalism and benevolence, which emphasize concern for the welfare of others. ${ }^{39}$ This also appears to be the pattern, albeit a weak one, in our data.

It had been shown previously that among Holocaust rescuers, women and men report different motivational patterns: for women, the emphasis was on their relationship with the person they were helping, while men more often cite "a sense of justice and personal power in overcoming evil forces." ${ }^{40}$ Both the higher ranking of Power and Achievement by men and the higher ranking of Benevolence and Universalism by women in our study are consistent with this interpretation. However, as in the large international study cited above, these differences in our study are small; in fact, they are trends that do not reach the level of statistical reliability.

A study by Shalom Schwartz, Lilach Sagiv, and Klaus Boehnke ${ }^{41}$ showed that certain values are associated with micro-worry (concern about self and its extensions), while others are associated with macro-worry (concern about society and the world). In particular, high priority for values such as Benevolence and Universalism was correlated with high macro-worry and low micro-worry, while priority for values such as Power and Achievement was correlated with the opposite pattern. The findings from the current study, viewed in conjunction with the results of Schwartz et al., suggest that Holocaust rescuers show a greater focus on wider society and worldly concerns than resistance members, although both groups were well aware of the need for control (Power). Again, this finding is consistent with previous research suggesting that Holocaust rescuers are characterized by a view of a shared humanity, ${ }^{42}$ including all individuals in the same group as themselves and thereby making the concerns of others and of society in general more relevant to themselves as well.

Besides adducing the confirmation of quantitative data analyses to earlier impressionistic conclusions, our findings shed new light on the motivational characteristics of members of different components of the anti-Nazi resistance. They also point to the importance of stable personality factors, such as values, in the response 
to tyranny and persecution, contrary to theories that claim the dominance of situational variables. ${ }^{43}$ A fuller understanding of these factors could enable democratic societies to foster the qualities that enhance both humanitarian and armed resistance to future genocidal regimes.

\section{Acknowledgments}

This research was made possible by grants to the first author from the Social Sciences and Humanities Research Council of Canada and by the help of the US Holocaust Memorial Museum, Washington, DC; the Imperial War Museum, London, UK; and the European Resistance Archive, Berlin, Germany. We are also grateful to Lindi Cassel, Sabrina Chang, and Rajiv Jhangiani for their assistance in scoring material for reliability and in analyzing the data. Communications should be addressed to Peter Suedfeld at psuedfeld@psych.ubc.ca or at the Department of Psychology, UBC, 2136 West Mall, Vancouver, BC V6T 1 Z4 Canada.

\section{Notes}

1. Samuel P. Oliner and Pearl M. Oliner, The Altruistic Personality: Rescuers of Jews in Nazi Europe (New York: Free Press, 1988).

2. Mordecai Paldiel, "The Altruism of the Righteous Gentiles," Holocaust and Genocide Studies 3 (1988): 187-96.

3. Martin Gilbert, The Righteous: The Unsung Heroes of the Holocaust (New York: Holt, 2003).

4. Oliner and Oliner, The Altruistic Personality.

5. Ibid., 175 .

6. Selwyn W. Becker and Alice H. Eagly, "The Heroism of Women and Men," American Psychologist 59 (2004): 163-78; Kristen Renwick Monroe, "John Donne's People: Explaining Differences between Rational Actors and Altruists through Cognitive Frameworks," Journal of Politics 53 (2001): 394-433; Kristen Renwick Monroe, Michael C. Barton, and Ute Klingemann, "Altruism and the Theory of Rational Action: Rescuers of Jews in Nazi Europe,” Ethics 101 (1990): 103-22; Kristen Renwick Monroe and C. Epperson, “'But What Else Could I Do?' Choice, Identity and a Cognitive-Perceptual Theory of Ethical Political Behavior," Political Psychology 15 (1994): 201-26; S.T. Shepela, "Courageous Resistance: A Special Case of Altruism," Theory and Psychology 9 (1999): 787-805.

7. Kristen Renwick Monroe, The Heart of Altruism: Perceptions of a Common Humanity (Princeton, NJ: Princeton University Press, 1996); Monroe et al., "Altruism."

8. Elizabeth Midlarsky, Stephanie F. Jones, and Robin P. Corley, "Personality Correlates of Heroic Rescue during the Holocaust," Journal of Personality 73 (2005): 907-34.

9. E.g., ibid.; Oliner and Oliner, The Altruistic Personality.

10. "Narodowe Sily Zbrojne" (Simon Wiesenthal Center Multimedia Learning Center Online, 1997), http://motlc.learningcenter.wiesenthal.org/pages/t053/t05323.html (accessed 3 January 2008).

11. Nechama Tec, Resilience and Courage: Women, Men, and the Holocaust (New Haven, CT: Yale University Press, 2003); "Armia Krajowa” (Simon Wiesenthal Center Multimedia Learning Center Online, 1997), http://motlc.learningcenter.wiesenthal.org/pages/t002/ t00215.html (accessed 3 January 2008).

12. E.g., Tec, Resilience and Courage.

13. US Holocaust Memorial Museum, Resistance during the Holocaust (Washington, DC: US Holocaust Memorial Museum, n.d.), http://www.ushmm.org/education/foreducators/ resource/resistance.pdf (accessed 3 January 2008).

14. Louis A. Gottschalk, Content Analysis of Verbal Behavior: New Findings and Clinical Applications (Hillsdale, NJ: Lawrence Erlbaum, 1995); Robert C. North, Ole R. Holsti, M. George Zaninovich, and Dina A. Zinnes, Content Analysis: A Handbook with 
Applications for the Study of International Crisis (Evanston, IL: Northwestern University Press, 1963); Charles P. Smith with John W. Atkinson, David C. McClelland, and Joseph Veroff, eds., Motivation and Personality: Handbook of Thematic Content Analysis (New York: Cambridge University Press, 1992).

15. E.g., Gottschalk, Content Analysis; Smith et al., Motivation and Personality.

16. Shalom H. Schwartz. "Universals in the Content and Structure of Values: Theoretical Advances and Empirical Tests in 20 Countries," in Advances in Experimental Social Psychology, vol. 25, ed. Mark P. Zanna, 1-65 (San Diego, CA: Academic Press, 1992).

17. Shalom H. Schwartz and Anat Bardi, "Value Hierarchies Across Cultures: Taking a Similarities Perspective," Journal of Cross-Cultural Psychology 32 (2001): 268-90.

18. Naomi Struch, Shalom H. Schwartz, and Willem A. van der Kloot, "Meanings of Basic Values for Women and Men: A Cross-Cultural Analysis," Personality and Social Psychology Bulletin 28 (2002): 16-28.

19. Becker and Eagly, "Heroism"; Monroe, Heart of Altruism; Monroe and Epperson, "But What Else"; Monroe et al., "Altruism"; Oliner and Oliner, The Altruistic Personality; Shepela et al., "Courageous Resistance."

20. Oliner and Oliner, The Altruistic Personality; Midlarsky et al., "Personality Correlates."

21. Oliner and Oliner, ibid.

22. Ibid.; Kristen Renwick Monroe, The Hand of Compassion: Portraits of Moral Choice During the Holocaust (Princeton, NJ: Princeton University Press, 2004).

23. Midlarsky et al., "Personality Correlates."

24. Schwartz and Bardi, "Value Hierarchies."

25. Gay Block and Malka Drucker, Rescuers: Portraits of Moral Courage in the Holocaust (New York: Holmes \& Meier, 2004).

26. Mark Klempner, The Heart Has Reasons: Holocaust Rescuers and Their Stories of Courage (Cleveland, OH: Pilgrim Press, 2006).

27. Monroe, Hand of Compassion.

28. United States Holocaust Memorial Museum, Library and Archives Catalogue, http://www.ushmm.org/research/library/ (accessed 11 December 2005-27 February 2006).

29. European Resistance Archive, Video Archive, http://www.resistance-archive.org/en/ testimonies (accessed 10 May 2007).

30. Schwartz and Bardi, "Value Hierarchies."

31. See, e.g., Gilbert, The Righteous; Richard Rashke, Escape from Sobibor (New York: Avon, 1982); Mordecai Paldiel, Sheltering the Jews: Stories of Holocaust Rescuers (Minneapolis, MN: Fortress Press, 1996).

32. Schwartz and Bardi, "Value Hierarchies."

33. Ibid.

34. Ibid.

35. Monroe et al., "Altruism"; Monroe, "John Donne's People"; Monroe, Heart of Altruism; Oliner and Oliner, The Altruistic Personality.

36. Oliner and Oliner, ibid.

37. M. Clever and J.W. Boyer, eds., Resistance Against the Third Reich 1933-1990 (Chicago: University of Chicago Press, 1992).

38. Schwartz and Bardi, "Value Hierarchies."

39. Shalom H. Schwartz and Tammy Rubel, "Sex Differences in Value Priorities: CrossCultural and Multimethod Studies," Journal of Personality and Social Psychology 89 (1996): 1010-28.

40. V.L. Anderson. "Gender Differences in Altruism among Holocaust Rescuers," Journal of Social Behavior and Personality 8 (1993): 43-58.

41. Shalom H. Schwartz, Lilach Sagiv, and Klaus Boehnke, "Worries and Values," Journal of Personality 68 (2000): 309-46.

42. Monroe, "John Donne's People"; Monroe, Heart of Altruism.

43. Philip Zimbardo, The Lucifer Effect: Understanding How Good People Turn Evil (New York: Random House, 2007). 